\title{
Biopsy sampling during self-expandable metallic stent placement in acute malignant colorectal obstruction: a narrative review
}

Sigrid Skov Bennedsgaard ${ }^{*}$ (1) and Lene Hjerrild Iversen

\begin{abstract}
Background: Histopathology is a crucial part of diagnosis and treatment guidance of colorectal cancer. In Denmark, it is not routine to biopsy during self-expandable metallic stent (SEMS) placement as a treatment option for acute colorectal obstruction of unknown etiology. This is due to lack of knowledge about the risks of hemorrhage, and thus the risk to aggravate the deteriorating overview conditions. Therefore, the aim of this study is to investigate whether there is evidence to avoid biopsy sampling during acute SEMS placement.

Methods: The PubMed, Embase, and Cochrane Library databases were searched for relevant studies. Studies were included if they described biopsy sampling in relation to SEMS placement. Additionally, national and international guidelines were scrutinized on Google and by visiting the websites of national and international gastrointestinal societies.

Results: In total, 43 studies were included in the review. Among these, one recommended biopsy during SEMS placement, three advised against biopsy, 23 just reported biopsy was performed during the procedure, and 16 reported biopsy before or after the procedure, or the timing was not specified. Among the 12 included guidelines, only two described biopsy during SEMS placement.

Conclusion: The literature on the subject is limited. In 24 of the 43 included studies, biopsy sampling was done during SEMS placement without reporting a decrease in the technical success rate. The included guidelines were characterized by a general lack of description of whether biopsy during SEMS placement should be performed or not. Prospective studies are needed in order to establish the real risk of hemorrhage, if any, when a biopsy is obtained.
\end{abstract}

Keywords: Self-expandable metallic stent, SEMS, Colorectal stenting, Endoscopy, Colorectal cancer, Biopsy, Obstruction, Guidelines

\section{Background}

Colorectal cancer is the third most common type of cancer in the world and with high incidence rates in Europe, Australia/New Zealand, Northern America, and Eastern Asia [1]. Despite increased screening efforts, around 14\%

\section{* Correspondence: au521893@uni.au.dk

Department of Surgery, Aarhus University Hospital, Aarhus, Denmark of Danish colorectal cancer patients present with a colorectal obstruction which necessitates acute care [2].

At the onset of acute colorectal obstruction, patients are often fluid and electrolyte deranged [3]. Acute bowel resection is associated with a significantly increased postoperative mortality. Thus, a diverting procedure as bridge-to-surgery can be favorable. This can be either a

(c) The Author(s). 2021 Open Access This article is licensed under a Creative Commons Attribution 4.0 International License, which permits use, sharing, adaptation, distribution and reproduction in any medium or format, as long as you give appropriate credit to the original author(s) and the source, provide a link to the Creative Commons licence, and indicate if changes were made. The images or other third party material in this article are included in the article's Creative Commons licence, unless indicated otherwise in a credit line to the material. If material is not included in the article's Creative Commons licence and your intended use is not permitted by statutory regulation or exceeds the permitted use, you will need to obtain permission directly from the copyright holder. To view a copy of this licence, visit http://creativecommons.org/licenses/by/4.0/ The Creative Commons Public Domain Dedication waiver (http://creativecommons.org/publicdomain/zero/1.0/) applies to the data made available in this article, unless otherwise stated in a credit line to the data. 
diverting stoma or placement of a self-expandable metallic stents (SEMS) [4]. Patients presenting with acute obstruction due to colorectal cancer more often have distant metastases than colorectal cancer patients who are diagnosed in an elective setting $[4,5]$. In case of distant metastases, SEMS placement might be the definitive procedure, similarly, if patients turn out to be unfit for bowel resection [5].

Nowadays, the SEMS placement procedure in the great majority is done by inserting a flexible metal grid tube over a guide through the obstruction via an endoscope. The technical success rate of the SEMS placement is about $86 \%$ [6] and naturally depends of a clear visual field in the lumen of the colon. The procedure is also affected by the location of the malignancy, since sharply angulated or proximal anatomic locations can make it technically difficult [7]. SEMS-related complications can be perforation, stent migration, re-obstruction, bleeding, and pain [8]. An essential benefit is that the SEMS placement gives an immediate relief of obstruction and gives the possibility for the patient to be examined, get normalized fluid and electrolytes balance, become optimized of comorbidities, and undergo elective surgery $[3,5]$.

In order to be able to manage the patient optimally, it is necessary to know the histological diagnosis. For the great majority of patients not presenting with an acute obstruction, a biopsy is usually obtained during the elective diagnostic colonoscopy [9]. In Denmark, it has been the standard at most centers to refrain from biopsy of the tumor during SEMS placement in the acute setting, in order to avoid aggravating the already poor overview conditions with also hemorrhage-and thus possibly lose the opportunity to place the SEMS, i.e., technical failure of SEMS placement [2].

Nonetheless, if SEMS is the definitive treatment, a biopsy is needed to ensure that it is a malignant tumor as well as the histological type [10]. If no biopsy is taken from the tumor during the SEMS placement procedure, it is later on necessary to do biopsy sampling. This prolongs the process of investigation, which is not conducive for the patient.

The Danish guidelines for the diagnosis and treatment of colorectal cancer have been prepared by the Danish Colorectal Cancer Group (DCCG) [2]. The issue of biopsy sampling while placing the SEMS as a treatment for acute malignant obstruction has not been addressed in the Danish guidelines. The aim of the present study was to conduct a narrative review to investigate whether there is evidence to avoid biopsy sampling during acute SEMS placement. Further, we searched international guidelines to scrutinize their recommendations for biopsy sampling during acute SEMS placement.

\section{Methods}

This narrative review was performed according to the PRISMA Statement [11] as appropriate.

\section{Eligibility criteria}

We considered studies focusing on the procedure of SEMS placement in which biopsy sampling was addressed. A restriction was placed on the year of publication, excluding publications earlier than 1990. The language was set to English only. In the Embase database, publication types were restricted to article, review, and article in press.

Studies were excluded if the study was (1) not about colorectal cancer, (2) not about SEMS placement, (3) not using a standard SEMS (e.g., biodegradable stent), (4) not using colonoscopy, (5) not performed in an acute setting, or there was (6) no access to the full text publication via the institution of Aarhus University.

\section{Information sources and search}

The PubMed and Embase databases were used to find studies focusing on the procedure of acute SEMS placement. The literature searches in the two databases were conducted on November 28 and December 3, 2020, respectively, by using four search strings (Additional file 1) for a more thorough search. Furthermore, Cochrane Library was searched for reviews regarding acute SEMS placement on December 7, 2020 (Additional file 1).

\section{Study selection}

All the studies were transferred to Endnote ${ }^{\mathrm{Tu}} \mathrm{X} 9$, a reference management software. Then, they were transferred to the website www.covidence.org (Covidence), where the screening was done. This is an online software that can be used to organize and improve the efficiency of the screening. First, Covidence was used for the title and abstract screening and then the full text screening.

Studies identified by the searches were screened, assessed, and included according to the PRISMA statement and the Covidence directions [37]. The studies were screened by title and abstract based on the eligibility criteria.

The remaining studies went through full text screening. They were reviewed in order to assess whether they described biopsy sampling or not. It was quickly discovered that if the studies described biopsy sampling, it was only with a few words. Therefore, the search function in the PDF file was used to search for the following words, one at a time: "biops", "needle", "histolog"", "sample", "tissue", and "patholog*". If the word was to be found in the study, it would be highlighted. This was the most efficient way to do the full text screening. Those that did not describe biopsy sampling at all were excluded. Studies that described biopsy sampling, but not during SEMS 
Table 1 Biopsy during SEMS placement procedure

\begin{tabular}{|c|c|c|c|c|c|c|c|}
\hline First author & Country & Year & $\begin{array}{l}\text { Study } \\
\text { type }\end{array}$ & $n$ & $\begin{array}{l}\text { Type of } \\
\text { endoscopist }\end{array}$ & Location of malignancy & $\begin{array}{l}\text { Recommends } \\
\text { biopsy }\end{array}$ \\
\hline Alshammari [12] & Saudi Arabia & 2020 & $C R$ & 1 & GE & Left colon & N/A \\
\hline Berselli [13] & Italy & 2019 & RS & 33 & GE & Left colon, splenic, or hepatic flexure & N/A \\
\hline Bonfante [14] & Italy & 2012 & RS & 45 & S & Left colon, rectum & N/A \\
\hline Donlon [15] & Ireland & 2019 & RS & 103 & N/A & All locations & N/A \\
\hline Dulucq [16] & France & 2006 & PS & 14 & GE & Left colon, right colon, rectum & N/A \\
\hline Feo [17] & USA & 2011 & $\mathrm{R}$ & - & N/A & Left colon, right colon & N/A \\
\hline $\begin{array}{l}\text { Fernández-Esparrach } \\
\text { [18] }\end{array}$ & Spain & 2010 & RS & 39 & GE & Left colon, rectum & N/A \\
\hline Gianotti [19] & Italy & 2013 & PS & 83 & GE & Left colon, right colon & N/A \\
\hline Han [20] & China & 2020 & RS & 14 & S & Left colon, splenic flexure & N/A \\
\hline Jost [21] & Switzerland & 2007 & RS & 67 & N/A & Left colon, splenic flexure, rectum & Yes \\
\hline Keymling [39] & Germany & 2003 & $\mathrm{R}$ & - & N/A & All locations & N/A \\
\hline Kuwai [22] & Japan & 2018 & PS & 501 & N/A & Left colon, right colon & N/A \\
\hline Könes [23] & Turkey & 2019 & RS & 21 & GS & Splenic or hepatic flexure & N/A \\
\hline Lee [24] & South Korea & 2012 & RS & 88 & GE & Left colon, right colon, rectum & N/A \\
\hline Li [40] & China & 2019 & RS & 26 & GE & Left colon, splenic flexure, rectum & N/A \\
\hline Liu [25] & China & 2019 & $C R$ & 6 & CS & Left colon, rectum & N/A \\
\hline Matsuda [26] & Japan & 2016 & RS & 28 & CS & Left colon, right colon, rectum & N/A \\
\hline Matsuda [27] & Japan & 2019 & RS & 25 & S & Left colon, right colon, rectum & N/A \\
\hline Matsuzawa [28] & Japan & 2015 & PS & 513 & GE & All locations & No \\
\hline Pacheco-Barcia [29] & Spain & 2019 & RS & 78 & N/A & Left colon, transverse colon & N/A \\
\hline Repici [30] & Italy & 2006 & $\mathrm{R}$ & - & N/A & Left colon, right colon & N/A \\
\hline Repici [31] & Italy & 2008 & PS & 42 & N/A & All locations & N/A \\
\hline Saito [32] & Japan & 2015 & PS & 296 & N/A & Left colon, right colon, rectum & No \\
\hline Soto [33] & Spain & 2006 & RS & 62 & N/A & Left colon, right colon, rectum & N/A \\
\hline Stipa [34] & Italy & 2007 & PS & 30 & N/A & $\begin{array}{l}\text { Left colon, splenic or hepatic flexure, } \\
\text { rectum }\end{array}$ & N/A \\
\hline Tomita [35] & Japan & 2019 & PS & 404 & N/A & Left colon, right colon, rectum & No \\
\hline van den Berg [36] & $\begin{array}{l}\text { The } \\
\text { Netherlands }\end{array}$ & 2014 & RS & 59 & GE & Left colon, right colon, splenic flexure & N/A \\
\hline
\end{tabular}

Study type: $C R$ case report, $R S$ retrospective study, $P S$ prospective study, $R$ review

Type of endoscopist: GE gastroenterologist, CS colorectal surgeon, GS general surgeon, $S$ surgeon (not specified)

placement, were categorized as "before," "after," or "N/ $\mathrm{A}$ " and then included. The category "before" means that the biopsy was obtained at a separate procedure, prior to the SEMS placement. The category "after" means that the biopsy was obtained at a separate procedure, after the SEMS placement was done. The category "N/A" means that the timing of the biopsy was not specified in the study.

Since the literature on the subject was so sparse, we chose to include reviews and case reports.

\section{Additional search: guidelines}

To scrutinize guidelines on management of acute colorectal obstruction, we decided to include guidelines from countries close to Denmark (Sweden,
Norway, Germany, and The Netherlands) in order to limit the number of included guidelines. Next, we included guidelines from the same countries as where the included studies originated. Thereby, it was possible to evaluate whether there was a relation between what was stated in the guidelines and what was done in practice in the studies.

To find guidelines from the selected countries and international gastrointestinal societies, it was necessary to search on Google. The words "colorectal cancer", "gastroenterology", "society", and "guidelines" were used in combination with the name of the country. Other relevant societies were found on International Society Listings on www.esge.com, www.worldgastroenterology. org, and www.fascrs.com. 
The guidelines were transferred to Endnote ${ }^{\mathrm{mix}}$ X9. Each guideline was reviewed in order to find out whether SEMS placement was described and if it was recommended. If so, the aim was to determine whether the guideline recommended biopsy sampling during acute SEMS placement. If the guideline recommended or did not recommend biopsy sampling, then the level of evidence was assessed using the Oxford Centre for Evidence-Based Medicine-Levels of Evidence [38].

\section{Results}

\section{Study selection}

Searches 1 and 2 (PubMed) yielded 776 studies (Fig. 1). Of these, 75 duplicates were removed, and 458 studies were excluded based on at least one of the exclusion criteria. Then, the remaining 243 studies went through full text screening, among which 19 studies were excluded because there was no access to the full text via the institution of Aarhus University. Besides that, 186 were excluded because they did not mention biopsy sampling. In these searches, 25 studies described biopsy sampling during SEMS placement, and 13 studies mentioned biopsy sampling before or after SEMS placement, or the time was not specified. These 38 studies were included in the study.

Searches 3 and 4 (Embase) yielded 619 studies (Fig. 1). A total of 218 duplicates were found by using Covidence and were excluded before the screening was initiated. Of the remaining 401 studies, 354 were excluded based on at least one of the exclusion criteria. During the full text screening, three guidelines were excluded, since they were outdated. Ten studies were excluded because there was no full text available, and 29 were excluded because they did not mention biopsy sampling. Two studies described biopsy sampling during SEMS placement, and three studies did not specify the timing of the biopsy. These five studies were included in the study.

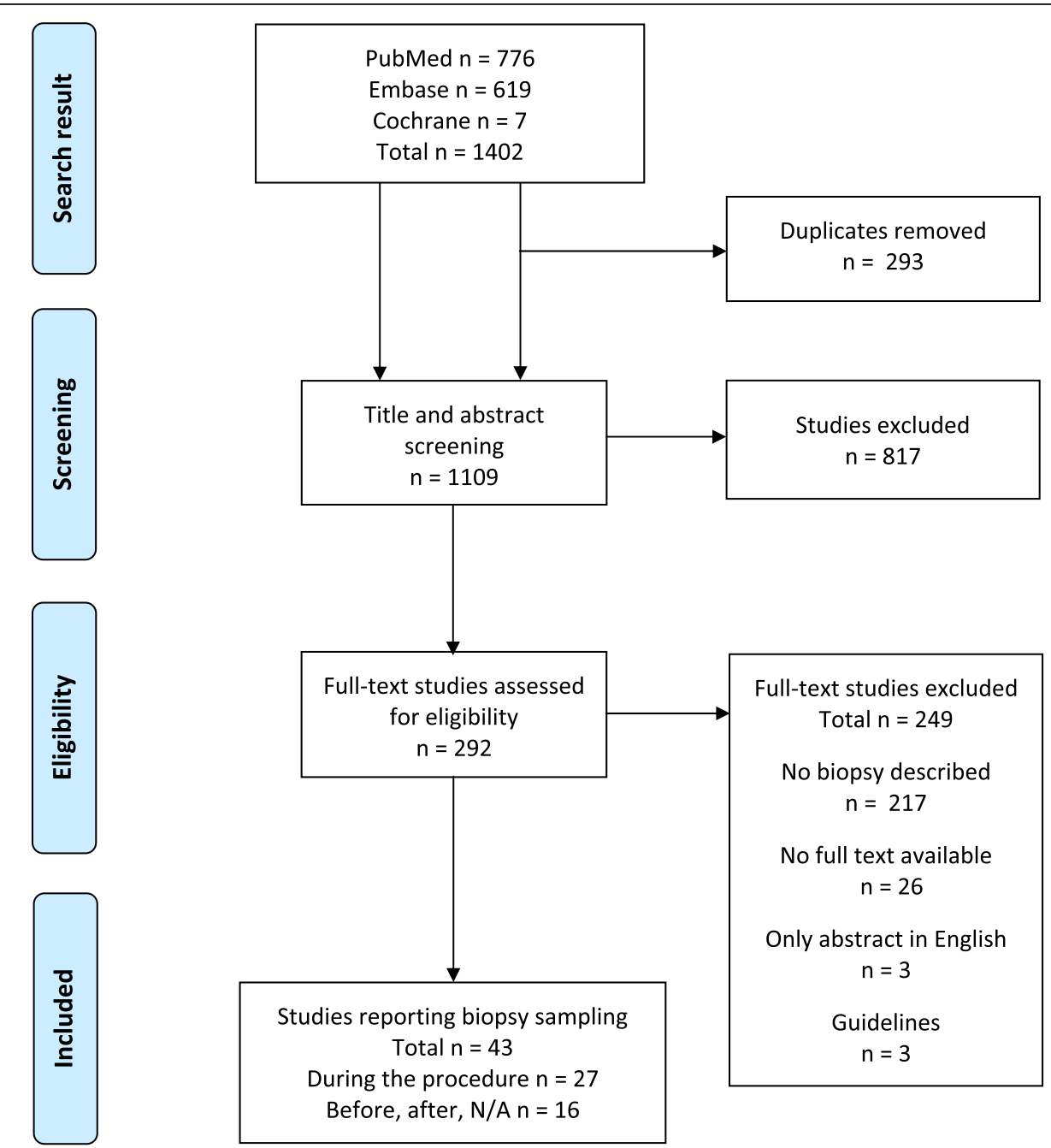

Fig. 1 Flow chart showing the screening, assessment, and inclusion of the studies according to the PRISMA Statement [11] 
The Cochrane Library search yielded 7 reviews. Five were excluded during the title and abstract screening. The remaining two reviews were excluded in the full text screening, since they did not mention biopsy sampling.

In total, the searches yielded 43 studies that described biopsy sampling: 27 reported biopsy during SEMS placement, and 16 reported biopsy before or after the procedure or not specified (Fig. 1).

\section{Study characteristics}

The literature searches yielded 20 retrospective and ten prospective cohort studies, eight reviews, five case reports, no cross sectional studies, and no randomized studies.

Despite that several studies addressed SEMS placement, both as bridge-to-surgery and as palliation, a description of biopsy sampling during the procedure was seldom included. In total, 27 studies that described biopsy sampling during SEMS placement were included in the study (Table 1). The number of patients was rather low in the majority of studies.

The included studies were from 17 different countries. Three studies [28, 32, 35], all from Japan, recommended to omit biopsy during SEMS placement. One of the three studies was the prospective cohort study by Matsuzawa et al. [28]. During the study period, the research group made a website with a brief guideline [41] for SEMS placement. It was this particular guideline the three studies based their recommendations on. Another one of the three studies was Saito et al. [32], a prospective cohort study with 312 patients. The authors reported that biopsy sampling during the procedure was not recommended: "To maintain good visualization of the tumor orifice, biopsy immediately before SEMS placement was not recommended because the tumor orifice becomes obscure due to bleeding." [32].

The opposite was stated in the study of Kuwai et al. [22]. This study was a prospective cohort study with 511 patients. The study analyzed factors related to difficult SEMS placement. There were 10 technical failures, so the analysis was done on the remaining 501 patients. One of the analyzed factors was biopsy right before placing the SEMS. The study included both a univariate and a multivariate analysis of relationships between interventional practices and technically difficult SEMS placement procedures. The procedures were categorized as technically difficult, if the procedure time exceeded $45 \mathrm{~min}$. For performed biopsy sampling, the OR (95\% $\mathrm{CI})$ in the multivariate analysis was $1.4(0.88-2.19)$, i.e., no significant difference in the technical difficulty-as measured by prolonged procedure time.

In Jost et al. [21], SEMS placement with biopsy was recommended, but the recommendation should be characterized as an unjustified opinion only: "We recommend combined endoscopic and fluoroscopic guidance for colorectal stent placement for the following reasons: (a) a biopsy of the lesion can be taken and allows initial investigation with histology..." [21].

A total of 23 studies described biopsy during the SEMS placement procedure, but did not directly recommend biopsy during the procedure (Table 1). The 23 studies were included in this review, since it was not stated that the biopsy led to technical failure or a decrease in the technical success rate. Therefore, it was interpreted as safe to biopsy during the procedure.

The 16 studies that mentioned biopsy sampling, but not during the placement procedure, were also included (Table 2). These studies were included in the study because they might be able to provide insight in the clinical consequences of this treatment strategy. The studies showed that it is not only a Danish practice to refrain from biopsy during SEMS placement.

Even though most of the included studies reported the location of malignancy, i.e., right colon, left colon, or rectum, none of them addressed biopsy sampling in relation to the localization.

\section{Additional results: guidelines}

No guidelines from countries close to Denmark, i.e., Sweden, Norway, The Netherlands, nor Germany included any guidance of biopsy during SEMS placement. Guidelines from the same countries as the included studies were reviewed: Ireland, Great Britain, France, Czech Republic, Switzerland, Spain, Japan, Australia, and the USA. The European Society of Gastroenterology's (ESGE) guideline was reviewed because three of the included studies were from European countries that used the ESGE guideline.

It was not possible to find national guidelines in English from neither Italy, Turkey, Saudi Arabia, China, nor South Korea. When searching for the guidelines from these five countries, the relevant websites were in foreign languages. This made the search challenging.

In summary, we found one Danish guideline, one international guideline, and ten different national guidelines, which were included (Table 3).

Only two guidelines described biopsy sampling during SEMS placement $[41,62]$. One of these was the ESGE Clinical Guideline from 2020 [62]. In the ESGE guideline, biopsy during the SEMS placement procedure was described as a preferable procedure, since histopathology results can benefit the further management of the patient. However, the ESGE guideline stated that "...pathological confirmation of malignancy should not persistently be pursued in an urgent setting, such as during stent placement for acute colonic obstruction." In the guideline, the recommendation is categorized as a strong recommendation with low-quality evidence. 
Table 2 Biopsy before or after SEMS placement or time not specified

\begin{tabular}{|c|c|c|c|c|c|c|c|}
\hline First author & Country & Year & Study type & $n$ & Type of endoscopist & Location of malignancy & Recommends biopsy \\
\hline \multicolumn{8}{|c|}{ Time of biopsy: before } \\
\hline Fugazza [42] & Italy & 2017 & $\mathrm{R}$ & - & N/A & Left colon, right colon, rectum & $\mathrm{N} / \mathrm{A}$ \\
\hline \multicolumn{8}{|c|}{ Time of biopsy: after } \\
\hline Adler [43] & USA & 2002 & $C R$ & 1 & S & Rectum & $\mathrm{N} / \mathrm{A}$ \\
\hline Bayraktar [44] & Turkey & 2015 & RS & 49 & GS & Left colon, rectum & N/A \\
\hline Larkin [45] & Ireland & 2014 & PS & 44 & CS & All locations & N/A \\
\hline \multicolumn{8}{|c|}{ Time of biopsy: N/A } \\
\hline$A n[46]$ & China & 2020 & RS & 139 & s & Left colon, rectum & N/A \\
\hline Chung [47] & South Korea & 2012 & $C R$ & 1 & N/A & Left colon & N/A \\
\hline Dítě [48] & Czech Republic & 2003 & $\mathrm{R}$ & - & GE & Left colon, rectum & No \\
\hline Farkas [49] & UK & 2019 & $\mathrm{R}$ & - & N/A & Left colon & N/A \\
\hline Kaplan [50] & USA & 2014 & $\mathrm{R}$ & - & N/A & Left colon, right colon, rectum & N/A \\
\hline Kim [51] & South Korea & 2012 & RS & 14 & N/A & N/A & N/A \\
\hline $\mathrm{Li}[52]$ & China & 2019 & $C R$ & 1 & N/A & Left colon & N/A \\
\hline Öistämö [4] & Sweden & 2016 & RS & 20 & CS & Left colon, splenic flexure & N/A \\
\hline Parodi [53] & Italy & 2016 & RS & 88 & GE & Left colon, rectum & N/A \\
\hline Pisano [54] & Italy & 2018 & $\mathrm{R}$ & - & S & Left colon & Yes \\
\hline White [55] & Australia & 2011 & RS & 2 & N/A & Left colon & $\mathrm{N} / \mathrm{A}$ \\
\hline Yanar [56] & Turkey & 2014 & PS & 42 & N/A & Left colon, rectum & N/A \\
\hline
\end{tabular}

Study type: $C R$ case report, $R S$ retrospective study, $P S$ prospective study, $R$ review

Type of endoscopist: GE gastroenterologist, CS colorectal surgeon, GS general surgeon, $S$ surgeon (not specified)

The other guideline which described biopsy sampling was made by Japan Colonic Stent Safe Procedure Research Group. The guideline stated that biopsies should "be kept to an absolute minimum in order to secure the best possible visual field".

\section{Discussion}

We searched the literature to investigate whether there was evidence for avoiding biopsy during SEMS placement. The majority of the studies lacked detailed descriptions on when to biopsy, and what the risks might be. This challenged the assessment of the applicability of the studies. Three studies did not recommend biopsy during the procedure, one study recommended it, and 23 studies described biopsy sampling during SEMS placement without reporting a decrease in the technical success rate. Only one study, Kuwai et al. [22] included a statistical analysis of biopsy as a factor related to difficult SEMS placement. However, biopsy was not significantly associated with technical difficulties (defined as procedure time exceeding $45 \mathrm{~min}$ ) during the SEMS placement procedure.

These results leave one with the overall impression that biopsy can be performed safely during SEMS placement. Even so, the results were not strikingly convincing with only one study including statistical data analysis.
For the majority of studies, there was no information about when and how the surgeons got a tissue sample from the tumor. In some cases, they might have performed biopsy during the SEMS placement, but chose not to report it in the study because it was considered a normal procedure without interest to others. On the other hand, there could also be cases where they did not biopsy. Regarding to these cases, it would have been interesting to know why they did not biopsy. There might be the possibilities that biopsy during SEMS might be tried without success or be not widely known as surely safe. Information like these could improve the quality of present study and help clarify what kind of research needs to be done on the subject.

Only two guidelines described biopsy sampling [41, 62]. ESGE has a Guidelines Committee, and each guideline is made by a group of experts [67], which is considered a good quality of the guideline [62]. It should be noted that the guideline's references (in the section of interest) aimed to study brush cytology and biopsy sensitivity in general-not specifically during SEMS placement. Thus, it remains unclear on what basis the ESGE guideline recommends biopsy during the SEMS placement procedure, and the recommendation in present aspect must be considered weak.

The other guideline that described biopsy sampling was made by a Japanese research group [41]. The 
Table 3 Descriptions of and recommendations on SEMS in the included guidelines

\begin{tabular}{|c|c|c|c|c|c|}
\hline Country/society & Year & $\begin{array}{l}\text { Description of SEMS } \\
\text { placement }\end{array}$ & $\begin{array}{l}\text { Recommends SEMS as } \\
\text { treatment }^{\mathrm{a}}\end{array}$ & $\begin{array}{l}\text { Recommends } \\
\text { biopsy }^{\text {b }}\end{array}$ & $\begin{array}{l}\text { Evidence degree for } \\
\text { biopsy }^{\mathrm{b}}\end{array}$ \\
\hline Denmark [2] & 2019 & Yes & Yes & No & - \\
\hline Sweden [57] & 2020 & Yes & Yes & No & - \\
\hline Norway [58] & 2019 & Yes & Yes & No & - \\
\hline The Netherlands [59] & 2019 & Yes & Yes & No & - \\
\hline Germany [60] & 2019 & Yes & Yes & No & - \\
\hline Ireland [61] & 2017 & Yes & Yes & No & - \\
\hline Great Britain [61] & 2017 & Yes & Yes & No & - \\
\hline Switzerland [62] & 2020 & Yes & Yes & Yes & $\mathrm{D}$ \\
\hline Spain $[63,64]$ & $\begin{array}{l}2017 \\
2019\end{array}$ & $\begin{array}{l}\text { Yes } \\
\text { Yes }\end{array}$ & $\begin{array}{l}\text { Yes } \\
\text { Yes }\end{array}$ & $\begin{array}{l}\text { No } \\
\text { No }\end{array}$ & $\begin{array}{l}- \\
-\end{array}$ \\
\hline Czech Republic [62] & 2020 & Yes & Yes & Yes & $\mathrm{D}$ \\
\hline European Society (ESGE) [62] & 2020 & Yes & Yes & Yes & $\mathrm{D}$ \\
\hline $\begin{array}{l}\text { American Society (ASCRS) } \\
{[63,65]}\end{array}$ & $\begin{array}{l}2017 \\
2020\end{array}$ & $\begin{array}{l}\text { Yes } \\
\text { Yes }\end{array}$ & $\begin{array}{l}\text { Yes } \\
\text { Yes }\end{array}$ & $\begin{array}{l}\text { No } \\
\text { No }\end{array}$ & $\begin{array}{l}- \\
-\end{array}$ \\
\hline Japan [41] & 2015 & Yes & Yes & Yes & $\mathrm{D}$ \\
\hline France [62] & 2020 & Yes & Yes & Yes & $\mathrm{D}$ \\
\hline Australia [66] & 2018 & Yes & $\mathrm{Yes}^{\mathrm{c}}$ & No & - \\
\hline Saudi Arabia & - & - & - & - & - \\
\hline China & - & - & - & - & - \\
\hline South Korea & - & - & - & - & - \\
\hline Turkey & - & - & - & - & - \\
\hline Italy & - & - & - & - & - \\
\hline
\end{tabular}

guideline did not recommend biopsy during SEMS placement. However, the recommendation was without any references, except their own prospective cohort study. The guideline only explained briefly how hemorrhage during the procedure can make it difficult to identify the stenotic lumen.

Comparing the guidelines and studies from the same country showed no clear connection between what was described in the guidelines and what was done in the studies. The reason for this is uncertain. Maybe the decision on when to biopsy is usually made by the individual hospital/center. Or it might not be a high priority to include it in the guidelines.

The strengths of present study include the meticulous literature search and the systematic screening and assessment of the search results. Additionally, the study does not only assess studies but also national and international guidelines of relevance to the literature.

This review has limitations, among others, many of the studies completely lack information on when and how the biopsy was performed, and furthermore how the biopsy affects the procedure of treatment. Due to the absence of randomized trials, the study was based on retrospective and prospective cohort studies, reviews, and case reports. Therefore, it was not possible to yield any summary measures like risk ratio. Similarly, assessing risk of bias of the individual studies was challenged by the huge heterogeneity of the studies. Only one study aimed to analyse how biopsy affects SEMS placement. This made it difficult to make a proper comparison of the included studies.

Furthermore, a limitation of present study is the search for guidelines, which was difficult since there is no guideline database. Therefore, it was difficult to know for sure whether the search was adequate. In order to limit the number of guidelines, only countries close to Denmark and countries, where the included studies originated from, were included. This means that it was a selective, but well-defined review only of guidelines. 


\section{Conclusions}

We must conclude that the literature on recommendation for or against biopsy sampling during SEMS placement in acute malignant colorectal obstruction is very limited. No convincing evidence was found to avoid biopsy during SEMS placement-neither in the studies, nor the guidelines. Furthermore, this study showed that the majority of national guidelines lack recommendations on whether biopsy sampling should be performed or not during SEMS placement.

\section{Supplementary Information}

The online version contains supplementary material available at https://doi. org/10.1186/s12957-021-02122-8

Additional file 1. The search strings used in PubMed, Embase, and

Cochrane Library.

\section{Abbreviations \\ SEMS: Self-expandable metallic stent; ESGE: European Society of Gastroenterology}

\section{Acknowledgements}

Not applicable.

\section{Authors' contributions}

SSB conducted the literature search, reviewed all the studies and guidelines, and extracted the data. In the studies, where the biopsy method and timing was not clearly specified, the senior author, LHI, helped in reviewing the studies. The authors read and approved the final manuscript.

\section{Funding}

This publication has not received any funding.

\section{Availability of data and materials}

Data sharing is not applicable to this article as no datasets were generated or analyzed during the current study.

\section{Ethics approval and consent to participate}

Not applicable.

\section{Consent for publication}

Not applicable.

\section{Competing interests}

The authors declare that they have no competing interests.

Received: 21 September 2020 Accepted: 4 January 2021 Published online: 14 February 2021

\section{References}

1. Bray F, Ferlay J, et al. Global cancer statistics 2018: GLOBOCAN estimates of incidence and mortality worldwide for 36 cancers in 185 countries. CA Cancer J Clin. 2018;68:394-424. https://doi.org/10.3322/caac.21492.

2. Løve US, Avlund TH. Akut kirurgi - Behandling af colonileus og obstruktion; 2019. Available at: https://dccg.dk/wp-content/uploads/2019/11/Akutkirurgi-colon-ileus_AdmGodk_051119.pdf. Access date: 17 Nov 2020

3. Adler DG. Colonic strictures: dilation and stents. Gastrointest Endosc Clin N Am. 2015;25:359-71. https://doi.org/10.1016/j.giec.2014.11.001.

4. Öistämö E, Hjern F, et al. Emergency management with resection versus proximal stoma or stent treatment and planned resection in malignant leftsided colon obstruction. World J Surg Oncol. 2016;14:232. https://doi.org/10. 1186/s12957-016-0994-2.

5. Repici A, de Paula Pessoa Ferreira D. Expandable metal stents for malignant colorectal strictures. Gastrointest Endosc Clin N Am. 2011;21:511-33. https:// doi.org/10.1016/j.giec.2011.04.005.
6. Sagar J. Colorectal stents for the management of malignant colonic obstruction (review). Cochrane Libr. 2011. https://doi.org/10.1002/14651858. CD007378.pub2/.

7. Vázquez-Iglesias JL, Gonzalez-Conde B, et al. Self-expandable stents in malignant colonic obstruction: insertion assisted with a sphincterotome in technically difficult cases. Gastrointest Endosc. 2005;62:436-7. https://doi. org/10.1016/j.gie.2005.04.028.

8. Lee JM, Byeon JS. Colorectal stents: current status. Clin Endosc. 2015;48:194200. https://doi.org/10.5946/ce.2015.48.3.194.

9. Memorial Sloan Kettering Cancer Center The role of pathology. Available at: https://www.mskcc.org/cancer-care/diagnosis-treatment/diagnosing/rolepathology. Access date: 20 Nov 2020.

10. Memorial Sloan Kettering Cancer Center Colon cancer diagnosis. Available at: https://www.mskcc.org/cancer-care/types/colon/diagnosis. Access date: 20 Nov 2020.

11. Moher D, Liberati $A$, et al. Preferred reporting items for systematic reviews and meta-analyses: the PRISMA statement. PLoS Med. 2009;6:1-6. https:// doi.org/10.1371/journal.pmed.1000097.

12. Alshammari $T$, Alshammari $\mathrm{S}$, et al. Two histologically different primary malignancies: synchronous obstructive descending colon adenocarcinoma and appendicular carcinoid tumor. Am J Case Rep. 2020;21:e921810. https:// doi.org/10.12659/ajcr.921810.

13. Berselli M, Borroni G, et al. Laparoscopic approach to large bowel neoplastic obstruction after self-expandable-metal-stent (SEMS) placement. Surg Laparosc Endosc Percutan Tech. 2019;29:133-7. https://doi.org/10.1097/sle. 0000000000000623

14. Bonfante $P, D^{\prime} A m b r a ~ L$, et al. Managing acute colorectal obstruction by "bridge stenting" to laparoscopic surgery: our experience. World J Gastrointest Surg. 2012;4:289-95. https://doi.org/10.4240/wjgs.v4.i12.289.

15. Donlon NE, Kelly ME, et al. Colonic stenting as a bridge to surgery in malignant large bowel obstruction: oncological outcomes. Int J Colorectal Dis. 2019;34:613-9. https://doi.org/10.1007/s00384-019-03239-9.

16. Dulucq $J$ L, Wintringer $P$, et al. One-stage laparoscopic colorectal resection after placement of self-expanding metallic stents for colorectal obstruction: a prospective study. Dig Dis Sci. 2006;51:2365-71. https://doi.org/10.1007/ s10620-006-9223-0.

17. Feo L, Schaffzin DM. Colonic stents: the modern treatment of colonic obstruction. Adv Ther. 2011;28:73-86. https://doi.org/10.1007/s12325-0100094-6.

18. Fernández-Esparrach $\mathrm{G}$, Bordas JM, et al. Severe complications limit longterm clinical success of self-expanding metal stents in patients with obstructive colorectal cancer. Am J Gastroenterol. 2010;105:1087-93. https:// doi.org/10.1038/ajg.2009.660.

19. Gianotti L, Tamini N, et al. A prospective evaluation of short-term and long-term results from colonic stenting for palliation or as a bridge to elective operation versus immediate surgery for large-bowel obstruction. Surg Endosc. 2013;27:832-42. https://doi.org/10.1007/ s00464-012-2520-0.

20. Han JG, Wang ZJ, et al. Efficacy and safety of self-expanding metallic stent placement followed by neoadjuvant chemotherapy and scheduled surgery for treatment of obstructing left-sided colonic cancer. BMC Cancer. 2020;20:57. https://doi.org/10.1186/s12885-0206560-x.

21. Jost RS, Jost R, et al. Colorectal stenting: an effective therapy for preoperative and palliative treatment. Cardiovasc Intervent Radiol. 2007;30: 433-40. https://doi.org/10.1007/s00270-006-0012-0.

22. Kuwai T, Yamaguchi T, et al. Factors related to difficult self-expandable metallic stent placement for malignant colonic obstruction: a post-hoc analysis of a multicenter study across Japan. Dig Endosc. 2018;31:51-8. https://doi.org/10.1111/den.13260.

23. Köneş $\mathrm{O}$, Kartal $\mathrm{A}$, et al. Colonic stent use in patients with malignant flexure tumors presenting with obstruction. JSLS : J Soc Laparoendosc Surg. 2019; 23. https://doi.org/10.4293/JSLS.2018.00088.

24. Lee WS, Baek JH, et al. The outcome after stent placement or surgery as the initial treatment for obstructive primary tumor in patients with stage IV colon cancer. Am J Surg. 2012;203:715-9. https://doi.org/10.1016/j.amjsurg. 2011.05.015

25. Liu JJ, Ma TH, et al. Stent placement followed by preoperative chemotherapy and elective surgery for acute malignant colorectal obstruction: six cases of report. World J Gastrointestinal Oncol. 2019;11:264-9. https://doi.org/10.4251/wjgo.v11.i3.264. 
26. Matsuda A, Miyashita M, et al. Comparison between metallic stent and transanal decompression tube for malignant large-bowel obstruction. J Surg Res. 2016;205:474-81. https://doi.org/10.1016/j.jss. 2016.04.055.

27. Matsuda A, Miyashita M, et al. Colonic stent-induced mechanical compression may suppress cancer cell proliferation in malignant large bowel obstruction. Surg Endosc. 2019;33:1290-7. https://doi.org/10.1007/ s00464-018-6411-x

28. Matsuzawa $\mathrm{T}$, Ishida $\mathrm{H}$, et al. A Japanese prospective multicenter study of self-expandable metal stent placement for malignant colorectal obstruction: short-term safety and efficacy within 7 days of stent procedure in 513 cases. Gastrointest Endosc. 2015;82:697-707.e691. https://doi.org/10.1016/j.gie. 2015.03.1978.

29. Pacheco-Barcia $V$, Mondéjar R, et al. Safety and oncological outcomes of bevacizumab therapy in patients with advanced colorectal cancer and selfexpandable metal stents. Clin Colorectal Cancer. 2019;18:e287-93. https:// doi.org/10.1016/j.clcc.2019.05.009.

30. Repici A, Pagano N, et al. Metal stents for malignant colorectal obstruction. Minim Invasive Ther Allied Technol. 2006;15:331-8. https://doi.org/10.1080/ 13645700601037954

31. Repici A, De Caro G, et al. WallFlex colonic stent placement for management of malignant colonic obstruction: a prospective study at two centers. Gastrointest Endosc. 2008;67:77-84. https://doi.org/10.1016/j.gie. 2007.08.019.

32. Saito $S$, Yoshida $S$, et al. A prospective multicenter study on self-expandable metallic stents as a bridge to surgery for malignant colorectal obstruction in Japan: efficacy and safety in 312 patients. Surg Endosc. 2015;30:3976-86. https://doi.org/10.1007/s00464-015-4709-5.

33. Soto S, Lopez-Roses L, et al. Endoscopic treatment of acute colorectal obstruction with self-expandable metallic stents: experience in a community hospital. Surg Endosc. 2006;20:1072-6. https://doi.org/10.1007/s00464-0050345-9.

34. Stipa F, Pigazzi A, et al. Management of obstructive colorectal cancer with endoscopic stenting followed by single-stage surgery: open or laparoscopic resection? Surg Endosc. 2007;22:1477-81. https://doi.org/10.1007/s00464007-9654-5.

35. Tomita M, Saito $S$, et al. Self-expandable metallic stenting as a bridge to surgery for malignant colorectal obstruction: pooled analysis of 426 patients from two prospective multicenter series. Surg Endosc. 2019;33:499-509. https://doi.org/10.1007/s00464-018-6324-8.

36. van den Berg MW, Sloothaak DA, et al. Bridge-to-surgery stent placement versus emergency surgery for acute malignant colonic obstruction. $\mathrm{Br}$ J Surg. 2014;101:867-73. https://doi.org/10.1002/bjs.9521.

37. Covidence Support. Screening; 2019. Available at: https://support.covidence. org/help/screening. Access date: 26 Nov 2020

38. The Centre for Evidence-Based Medicine (2009), Oxford Centre for Evidence-Based Medicine: Levels of Evidence (March 2009). Available at: https://www.cebm.ox.ac.uk/resources/levels-of-evidence/oxfordcentre-for-evidence-based-medicine-levels-of-evidence-march-2009. Access date: 9 Dec 2020.

39. Keymling M. Colorectal stenting. Endoscopy. 2003;35:234-8. https://doi.org/ 10.1055/s-2003-37265.

40. Li W, Jin X, et al. The efficacy of endoscopic stenting combined with laparoscopy in the treatment of left colon cancer with obstruction. J Cancer Res Ther. 2019;15:375-9. https://doi.org/10.4103/jcrt.JCRT_111_18.

41. Colonic Stent Safe Procedure Group. Mini-guidelines (brief guidelines) for safe placement of colonic stents; 2015. Available at: https://colon-stent.com/ 001_mainpage_en.html. Access date: 2/12/2020

42. Fugazza A, Galtieri PA, et al. Using stents in the management of malignant bowel obstruction: the current situation and future progress. Expert Rev Gastroenterol Hepatol. 2017;11:633-41. https://doi.org/10.1080/17474124 2017.1309283.

43. Adler DG, Young-Fadok TM, et al. Preoperative chemoradiation therapy after placement of a self-expanding metal stent in a patient with an obstructing rectal cancer: clinical and pathologic findings. Gastrointest Endosc. 2002;55: 435-7. https://doi.org/10.1067/mge.2002.120108.

44. Bayraktar B, Ozemir $\mid A$, et al. Colorectal stenting for palliation and as a bridge to surgery: a 5-year follow-up study. World J Gastroenterol. 2015;21: 9373-9. https://doi.org/10.3748/wjg.v21.i31.9373.

45. Larkin JO, Moriarity AR, et al. Self-expanding metal stent insertion by colorectal surgeons in the management of obstructing colorectal cancers: a 6-year experience. Tech Coloproctol. 2014;18:453-8. https://doi.org/10.1007/ s10151-013-1073-0.

46. An $Y$, Wang $N$, et al. Efficacy of transanal drainage tube and self-expanding metallic stent in acute left malignant colorectal obstruction. Ann Palliat Med. 2020;9:1614-21. https://doi.org/10.21037/apm-19-458.

47. Chung MY, Park YS, et al. A case of colonic mucinous adenocarcinoma in 19-year-old male patient. Clin Endosc. 2012;45:103-7. https://doi.org/10. 5946/ce.2012.45.1.103

48. Dítě $\mathrm{P}$, Lata J, et al. Intestinal obstruction and perforation - the role of the gastroenterologist. Dig Dis. 2003;21:63-7. https://doi.org/10.1159/000071341.

49. Farkas NG, Welman TJP, et al. Unusual causes of large bowel obstruction. Curr Probl Surg. 2019;56:49-90. https://doi.org/10.1067/j. cpsurg.2018.12.001

50. Kaplan J, Strongin A, et al. Enteral stents for the management of malignant colorectal obstruction. World J Gastroenterol. 2014;20:13239-45. https://doi. org/10.3748/wjg.v20.i37.13239.

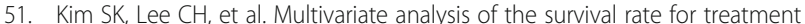
modalities in incurable stage IV colorectal cancer. J Korean Soc Coloproctol. 2012;28:35-41. https://doi.org/10.3393/jksc.2012.28.1.35.

52. Li ZL, Wang ZJ, et al. Successful treatment of obstructing colonic cancer by combining self-expandable stent and neoadjuvant chemotherapy: a case report. World J Clin Cases. 2019;7:335-9. https://doi.org/10.12998/wjcc.v7.i3. 335.

53. Parodi A, De Ceglie A, et al. Endoscopic stenting as bridge-to-surgery (BTS) in left-sided obstructing colorectal cancer: experience with conformable stents. Clin Res Hepatol Gastroenterol. 2016;40:638-44. https://doi.org/10. 1016/j.clinre.2016.03.007.

54. Pisano M, Zorcolo L, et al. 2017 WSES guidelines on colon and rectal cancer emergencies: obstruction and perforation. World J Emerg Surg. 2018:13:36. https://doi.org/10.1186/s13017-018-0192-3.

55. White SI, Abdool SI, et al. Management of malignant left-sided large bowel obstruction: a comparison between colonic stents and surgery. ANZ J Surg. 2011;81:257-60. https://doi.org/10.1111/j.1445-2197.2010. 05477.x.

56. Yanar H, Ozcinar B, et al. The role of colorectal stent placement in the management of acute malignant obstruction. Ulus Travma Acil Cerrahi Derg. 2014;20:23-7. https://doi.org/10.5505/tjtes.2014.39596.

57. Jung B., Johnsson A., et al. (2020), Tjock- och ändtarmscancer, Nationelt vårdprogram. Available at: https://kunskapsbanken.cancercentrum.se/ diagnoser/tjock-och-andtarmscancer/vardprogram/. Access date: 11/12/ 2020.

58. Helsedirektoratet. Nasjonalt handlingsprogram kreft i tykktarm og endetarm; 2019. Available at: https://www.helsedirektoratet.no/produkter?letter= JKL\&tema=retningslinje. Access date: 8/12/2020

59. Federate Medisch Specialisten. Colorectal cancer; 2019. Available at: https:// richtlijnendatabase.nl/en/richtlijn/colorectal_cancer/crc_-_screening.html Access date: 8/12/2020

60. Hohenberger W, Post S. Evidence based guideline for colorectal cancer (German guideline program in oncology); 2019. Available at: https://www. leitlinienprogramm-onkologie.de/fileadmin/user_upload/Downloads/ Leitlinien/Kolorektales_Karzinom/Version_2/GGPO_Guideline_Colorectal Cancer_2.1.pdf Access date: 8/12/2020

61. Moran B., Cunningham C., et al. (2017), Association of Coloproctology of Great Britain \& Ireland (ACPGBI): guidelines for the management of cancer of the colon, rectum and anus (2017) - Surgical Management. DOI: https:// doi.org/10.1111/codi.13704

62. Van Hooft JE, Veld JV, et al. Self-expandable metal stents for obstructing colonic and extracolonic cancer: European Society of Gastrointestinal Endoscopy (ESGE) guideline - update 2020. Endoscopy. 2020;52:389-407. https://doi.org/10.1055/a-1140-3017.

63. Vogel JD, Eskicioglu C, et al. The American Society of Colon and Rectal Surgeons clinical practice guidelines for the treatment of colon cancer. Dis Colon Rectum. 2017;60:999-1017. https://doi.org/10.1097/DCR. 0000000000000926

64. Benson $A B$, Venook $A P$, et al. NCCN clinical practice guidelines in oncology colon cancer; 2019. Available at: https://www.aecp-es.org/images/site/ documentos/GUIAS/1.pdf. Access date: 11/12/2020

65. You YN, Hardiman KM, et al. The American Society of Colon and Rectal Surgeons clinical practice guidelines for the treatment of rectal cancer. Dis Colon Rectum. 2020:63:1191-222. https://doi.org/10.1097/DCR. 0000000000001762 
66. Cancer Council Australia Colorectal Cancer Guidelines Working Party Luck $A$, et al. Clinical practice guidelines for the prevention, early detection and management of colorectal cancer; 2018. Available at: https://wiki.cancer.org.au/australia/Guidelines:Colorectal_cancer\#. Access date: 7/12/2020 2020

67. European Society of Gastrointestinal Endoscopy ESGE Guidelines

Committee. Available at: https:/www.esge.com/about-us/esge-committees/ esge-guidelines-committee/. Access date: 12/12/2020.

\section{Publisher's Note}

Springer Nature remains neutral with regard to jurisdictional claims in published maps and institutional affiliations.

Ready to submit your research? Choose BMC and benefit from:

- fast, convenient online submission

- thorough peer review by experienced researchers in your field

- rapid publication on acceptance

- support for research data, including large and complex data types

- gold Open Access which fosters wider collaboration and increased citations

- maximum visibility for your research: over $100 \mathrm{M}$ website views per year

At BMC, research is always in progress.

Learn more biomedcentral.com/submissions 